\title{
Effect of melatonin implants on secretion of luteinizing hormone in intact and castrated rams
}

\author{
J. R. Webster*, J. M. Suttie†, B. A. Veenvliet, T. R. Manley and \\ R. P. Littlejohn \\ MAFTech, Invermay Agricultural Centre, Private Bag, Mosgiel, New Zealand
}

\begin{abstract}
Summary. Rams were treated with melatonin implants in 2 experiments designed to examine the control of reproductive seasonality. In Exp. 1, rams $(n=12)$ were allocated to 3 treatment groups: 2 groups were treated with 2 melatonin implants per ram for 4 months from 11 November $(\mathrm{N})$ and 9 December $(\mathrm{D})$ and the remaining group was untreated $(\mathrm{C})$. The seasonal increase in luteinizing hormone (LH) pulse frequency and testes size was advanced in Groups $\mathrm{N}$ and $\mathrm{D}$. A second seasonal cycle in LH secretion and testes size occurred in Groups $\mathrm{N}$ and $\mathrm{D}$ after melatonin implants became exhausted. In Exp. 2, rams ( $n=20$ ) were allocated to 4 treatment groups: 10 rams were castrated on 6 October and 1 group of entire rams (EM) and one group of castrated rams (CM) were treated with 2 melatonin implants per ram each month from 3 November until 8 January. The other group of entire rams (EC) and castrated rams (CC) was untreated. An increase in LH pulse frequency occurred after castration. Melatonin treatment increased $\mathrm{LH}$ pulse frequency in entire rams and reduced $\mathrm{LH}$ pulse frequency in castrated rams. The results demonstrated that the advanced reproductive development as a result of treatment with melatonin implants was due to an effect of melatonin on the hypothalamic pulse generator to increase LH pulse frequency. The ability of melatonin to influence LH pulse frequency in entire and castrated rams indicated that an effect of melatonin on the hypothalamic pulse generator is independent of testicular steroids.
\end{abstract}

Keywords: melatonin; rams; luteinizing hormone; testes

\section{Introduction}

The onset of the breeding season in rams is characterized by an increase in the frequency of luteinizing hormone ( $\mathrm{LH})$ pulses detected in the peripheral circulation (Lincoln \& Short, 1980; Pelletier et al., 1982; Sanford et al., 1984). Each pulse of LH in peripheral blood is preceded by a pulse of gonadotrophin-releasing hormone $(\mathrm{GnRH})$ in hypophyseal portal blood (Caraty \& Locatelli, 1988), suggesting that the frequency of LH pulses is controlled by the hypothalamus. An increase in LH pulse frequency and testicular development can be induced by a reduction in photoperiod length from $16 \mathrm{~h}$ light: $8 \mathrm{~h}$ dark to $8 \mathrm{~h}$ light:16 h dark (Lincoln, 1976), indicating that photoperiodic entrainment of reproductive seasonality is mediated via the hypothalamus.

Photoperiodic entrainment of reproductive seasonality in sheep is achieved via melatonin secretion from the pineal gland (Arendt, 1986). Treatment of rams with melatonin implants during a long photoperiod stimulates testicular development in a way similar to that produced by a reduction in photoperiod length (Lincoln \& Ebling, 1985) and it would therefore be predicted that

*Present address: Reproductive Sciences Program, University of Michigan, 300 N Ingalls Building, 11th Floor, Ann Arbor, MI 48109-0404, USA.

†Reprint requests. 
melatonin exerts an effect via the hypothalamus. This appears to be true in ewes as an increase in the duration of melatonin infusion in pinealectomized ewes caused an increase in the frequency of LH pulses (Bittman et al., 1985). In contrast, treatment of ewes with melatonin during anoestrus advanced the onset of the breeding season yet caused no apparent increase in the frequency of LH pulses before the onset of oestrous cyclicity (Kennaway et al., 1982; Poulton et al., 1987). These latter observations have led to the suggestion that melatonin may affect reproductive responses by acting on neuroendocrine processes distinct from those regulating GnRH and gonadotrophin release (Poulton et al., 1987).

Steroids produced by the testes exert a strong inhibitory feedback action on the hypothalamus as indicated by the marked increase in the frequency of GnRH and LH pulses after castration (Caraty \& Locatelli, 1988). The ability of testosterone to inhibit LH secretion varies with changes in photoperiod length; a less strong steroid negative feedback is found during a short photoperiod ( $8 \mathrm{~h}$ light: $16 \mathrm{~h}$ dark) than during a long photoperiod $(16 \mathrm{~h}$ light: $8 \mathrm{~h}$ dark) (Pelletier \& Ortavant, 1975b; Lincoln, 1984), thus providing a mechanism whereby photoperiod may entrain the hypothalamic activity and reproductive state. Photoperiod-induced changes in LH secretion also occur in castrated rams (Pelletier \& Ortavant, 1975a; Lincoln, 1984), indicating that photoperiod can act directly on the hypothalamus.

The aim of the present experiments was to determine whether advancement of testicular development in rams by treatment with melatonin implants is associated with an increase in LH pulse frequency, thereby providing evidence for a hypothalamic site of action for melatonin. The role of steroid feedback in the action of melatonin on seasonality was also investigated by examining the effect of melatonin on the $\mathrm{LH}$ secretion in castrated and entire rams.

\section{Materials and Methods}

\section{Experiment 1}

Animals and management. Twelve Romney rams aged $\sim 1$ year were allocated to 3 treatment groups and maintained outside on pasture in one flock under natural photoperiodic conditions.

Treatments. Two groups of 4 rams were treated with 2 melatonin implants (18 mg melatonin; Regulin Ltd, Melbourne, Victoria, Australia) per ram at monthly intervals for 4 consecutive months from 11 November 1986 until 2 February 1987 (Group N) and from 9 December until 2 March (Group D). Implantation of ewes with one (Howse $e t$ al., 1987) or 2 (L. D. Staples, personal communication) melatonin implants has been demonstrated to raise plasma melatonin concentrations above normal nocturnal levels for at least 1 month. The remaining group of 4 rams was untreated (Group C).

Physical characteristics and blood sampling. The diameter of right and left testes was measured using Vernier calipers at weekly intervals from 7 November 1986 until 29 January 1988 . Serial blood samples $(10 \mathrm{ml})$ were collected through an indwelling jugular catheter from each ram before the start of treatment and at the end of each month thereafter until September 1987. For the pre-treatment and the 2 weeks after treatment, blood-sampling runs for Group $\mathrm{N}$ blood samples were taken every $15 \mathrm{~min}$ for $6 \mathrm{~h}$. Thereafter, the blood sampling protocol was altered and samples were collected every $30 \mathrm{~min}$ for $24 \mathrm{~h}$. Control rams were sampled on all occasions, in an identical manner to the other groups of rams. The blood was then centrifuged and the plasma removed and frozen until assayed for $\mathrm{LH}$. Blood samples at night were taken with the aid of a dim red light.

\section{Experiment 2}

Animals. Twenty Coopworth rams aged $\sim 1$ year were allocated to 4 treatment groups and maintained outside on pasture in one flock under natural photoperiodic conditions.

Treatments. Two groups of 5 rams were bilaterally castrated on 6 October. Castrations were performed under heavy sedation with xylazine hydrochloride (Rompun: Bayer NZ Ltd, Petone, NZ) at a dose rate of $0.2 \mathrm{mg} / \mathrm{kg}$ liveweight and using local anaesthetic, $2 \%$ lignocaine hydrochloride (xylocaine: Bayer NZ Ltd), in the scrotum and testes. Reversal of sedation after surgery was achieved using yohimbine hydrochloride (Sigma, St Louis, MO, USA). At 
monthly intervals from 3 November until 8 January one group of entire rams (Group EM) and one group of castrated rams (Group CM) were treated with 2 melatonin implants per ram. The remaining group of entire rams (Group EC) and group of castrated rams (Group CC) were untreated.

Physical characteristics and blood sampling. The diameter of right and left testes of entire rams was measured using Vernier calipers at weekly intervals from 1 October 1987 until 29 January 1988. Blood samples were collected through indwelling jugular catheters from all rams every $30 \mathrm{~min}$ for $24 \mathrm{~h}$ including a period of sampling every $10 \mathrm{~min}$ for $6 \mathrm{~h}$ between 16:00 and 22:00 h on 5 October, 2 November, 23 November, 14 December, 11 January and 4 February.

\section{LH assay}

Separate assays were used to analyse plasma LH concentrations because the pulse characteristics of rams and castrated rams differ. Plasma from rams was assayed in an assay with high sensitivity but a narrow-range standard curve as many of the samples were expected to have low or zero values for LH. In contrast, the castrated ram samples were analysed using a system of lower sensitivity but a greater range. No comparisons are made in the text between LH from rams and castrated rams.

Entire rams. Plasma $\mathrm{LH}$ concentration was measured by a homologous double-antibody radioimmunoassay based on that described by Niswender et al. (1969). The antiserum and antigen used were as described by Pelletier $e t$ al. (1982). The antiserum (No. 669, supplied by Dr Y. Combarnous, INRA, Nouzilly, France) was used at a final tube dilution of 1:450 000. The standard curve ranged from $0.156 \mathrm{ng} / \mathrm{ml}$ to $10 \mathrm{ng} / \mathrm{ml} \mathrm{LH}(\mathrm{Cy} 1085$, potency $=3.45 \times \mathrm{NIH}$ LH-SI, supplied by Dr Y. Combarnous) made up in plasma from rams (treated with medroxyprogesterone acetate (Sigma, St Louis, MO, USA) to reduce LH to non-detectable levels) to keep the matrix similar to the sample tubes. Assay blanks consisted of protein buffer (PBS buffer $+0.1 \%(w / v)$ BSA, plasma, antiserum and tracer. Assay sensitivity was defined as the $95 \%$ confidence interval of duplicate assay blanks and for Exp. 1 was $0.25 \mathrm{ng} / \mathrm{ml}$. Intra- and interassay coefficients of variation were 9.9 and $9.8 \%$, respectively, at $1.2 \mathrm{ng} / \mathrm{ml}$. In Exp. 2 assay sensitivity was $0.17 \mathrm{ng} / \mathrm{ml}$. Intra- and interassay coefficients of variation were 8.7 and $11.8 \%$, respectively, at $1.1 \mathrm{ng} / \mathrm{ml}$, and 6.9 and $9 \cdot 1 \%$, respectively, at $4 \cdot 7 \mathrm{ng} / \mathrm{ml}$.

Castrated rams. Plasma LH concentration was measured by a homologous double-antibody radioimmunoassay based on the protocol developed by Dr A. F. Parlow (Pituitary Hormones and Antisera Centre, Torrance, CA, USA) and supplied with the antiserum (NIADDK-anti-ovineLH-1, AFP-192279). The antiserum was used at a final tube dilution of $1: 2000000$. Cross-reactivities reported by Parlow for the antiserum were $5 \%$ with oFSH, $0.6 \%$ with oGH, $0.1 \%$ with bTSH and $0.001 \%$ with oPRL. The standard curve ranged from 0.625 to $20 \mathrm{ngLH} / \mathrm{ml}$ (Cy1085, potency = $3.45 \mathrm{mg} \times$ NIH-LH-S1, supplied by Dr Y. Combarnous, INRA, Nouzilly, France) made up in plasma from rams (treated with medroxyprogesterone acetate to reduce $\mathrm{LH}$ to non-detectable levels) to keep the matrix similar to the sample tubes. Assay blanks consisted of protein buffer (PBS buffer $+0 \cdot 1 \%(\mathrm{w} / \mathrm{v}) \mathrm{BSA}$ ), plasma, antiserum and tracer. Parallelism was confirmed by serial dilution of ram plasma with a high concentration of LH, with ram plasma (as used in the standard curve). Assay sensitivity was $0.30 \mathrm{ng} / \mathrm{ml}$. Intra- and interassay coefficients of variation were 12.1 and $20.6 \%$, respectively, at $1.17 \mathrm{ng} / \mathrm{ml}$, and 3.9 and $15.6 \%$, respectively, at $11.9 \mathrm{ng} / \mathrm{ml}$.

\section{Statistical analysis}

Testes diameter was calculated as the mean diameter of left and right testes.

Pulses of LH were detected using the method of Goodman \& Karsch (1980). The $95 \%$ confidence intervals for LH samples were calculated using an NIH radioimmunoassay computer program (MED-28, from the BCTIC computer code collection, contributed by V. B. Faden, J. C. Huston Jr, P. J. Munson and D. Rodbard of the NICHHD, NIH, Bethesda, MD, USA). Incomplete pulses at the beginning and end of the profiles were included in the analysis as pulses if the preceding rise or subsequent decline in LH concentration was significant.

In Exp. 1 the equation

$$
y=\mathrm{A} \sin (2 \operatorname{phi}(t-\mathrm{phi}) / \mathrm{P})+\mathrm{B} t+\mathrm{C}
$$

where $t$ is time (in weeks) from the start of measurement, phi is a phase parameter, $\mathrm{P}$ is a period parameter and $\mathrm{A}, \mathrm{B}$ and $\mathrm{C}$ are linear parameters, was used to model testis diameter and number of $\mathrm{LH}$ pulses. This was fitted for each treatment group and for each ram within treatment groups, and variance estimates, assuming independent normally distributed errors, are given at the ram stratum. This model is suitable for detecting phase differences between groups, but is not sufficiently flexible to accommodate large variations in amplitude between cycles within groups. Hence analysis of variance over treatment groups was also carried out for each observation time, and is used to supplement the curve-fitting analysis.

Differences between treatments were detected by univariate analysis of variance (ANOVA) using a GENSTAT statistical package at probability levels of less than $0.05\left({ }^{*}\right), 0.01\left({ }^{* *}\right)$ or $0.001\left({ }^{* * *}\right)$. Following a significant F-test, comparisons between the treatment groups were made using the LSD test. 


\section{Results}

\section{Experiment 1: effects of treatment of entire rams with melatonin implants in early summer}

Testes diameter. Parameter estimates from fitting Eqn (1) to testis diameter for each group are given in Table 1. There were gross differences in the fitted model between the control group, which completed only one period over the course of the trial, and the 2 melatonin-treated groups, both of which had 2 periods each of approximately half a year (Fig. 1). This led to estimates of phi, P and A which were significantly greater for the control group than for the other two groups.

Table 1. Parameter estimates (and their standard errors) obtained from fitting a sine curve with linear trend to mean testis diameter for each treatment group of rams

\begin{tabular}{|c|c|c|c|}
\hline Parameter & November & December & Control \\
\hline phi (phase) & $6.08 \quad(0.84)$ & $8.23 \quad(0.94)$ & $12 \cdot 2 \quad(1 \cdot 20)$ \\
\hline$P($ period $)$ & $26.0 \quad(0.72)$ & $26.7 \quad(0.80)$ & $43.9 \quad(2.20)$ \\
\hline A (linear) & $0.35 \quad(0.037)$ & $0.35 \quad(0.042)$ & $0.61 \quad(0.043)$ \\
\hline B (linear) & $0.011(0.0016)$ & $0.018(0.0018)$ & $0.009(0.0030)$ \\
\hline $\mathrm{C}$ (linear) & $4.13 \quad(0.06)$ & $3.97 \quad(0.07)$ & $4 \cdot 10 \quad(0 \cdot 10)$ \\
\hline
\end{tabular}

Residual standard deviation $=0.29$.

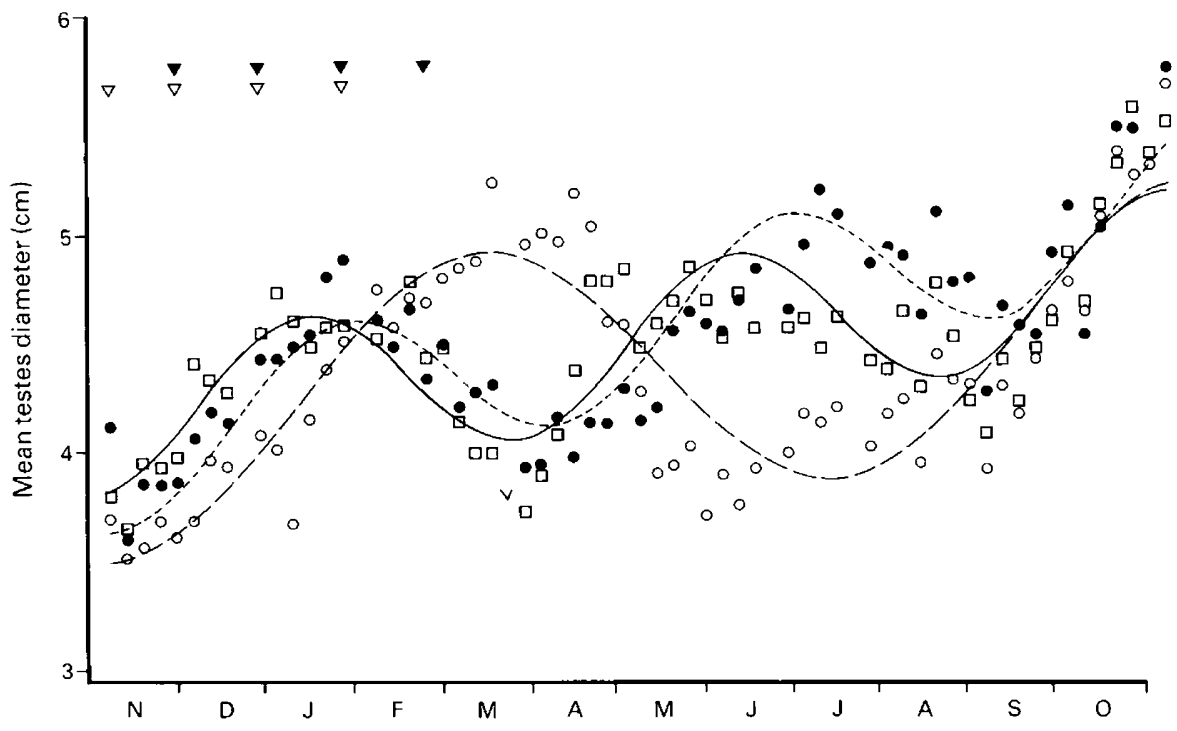

Fig. 1. Mean testes diameter for rams in Group $\mathrm{C}$ (control, $\mathrm{O}---\bigcirc$ ), Group $\mathrm{N}$ (melatonintreated, November start, $\square-\square$ ) and Group D (melatonin-treated, December start, - - ) in Exp. 1. The lines are the fitted curves from the expression

$$
y=\mathrm{A} \sin (2 \mathrm{phi}(t-\mathrm{phi}) / \mathrm{P})+\mathrm{B} t+\mathrm{C}
$$

where $t$ is time (in weeks) from the start of measurement, $\mathbf{P}$ is a period parameter, phi is a phase parameter and A, B and C are linear parameters. Open and closed symbol arrows indicate days when melatonin implants were given to rams in Groups $\mathrm{N}$ and $\mathrm{D}$, respectively.

Fitting separate models for Groups 1 and 2 lead to a significant improvement in the model $(F(5,469)=5.96)$, although only $B$ among the individual parameters differed significantly between groups. There was a tendency for Group $\mathrm{N}$ to have a stronger first peak and a weaker, earlier 
second peak than Group D, which is reflected in its smaller estimates for phi and B. Melatonin treatment accelerated testicular growth compared with control rams during summer and autumn, with the result that in December and January the testes diameter of Group $\mathrm{N}$ rams was larger than that of Group $\mathrm{C}$ rams $(P<0.05)$. On one occasion in January, the testes diameter of Group D was also greater than that of Group $\mathrm{C}(P<0.05)$. The testes size of the melatonin-treated rams reached a peak in February and testicular regression began approximately 3 months earlier than in control rams. Subsequently, the testes diameter of Groups $\mathrm{N}$ and $\mathrm{D}$ was less than that recorded for Group C during April and May $(P<0.05)$.

LH pulse frequency. LH pulse frequency was modelled by Eqn (1) with B $=0$, after rejecting the hypothesis $\mathbf{B}>0$. Parameter estimates are given in Table 2.

Table 2. Parameter estimates (and their standard errors) obtained from fitting a sine curve to luteinizing hormone pulse for each treatment group of rams

\begin{tabular}{lccc}
\hline Parameter & November & December & Control \\
\hline phi (phase) & $5.16(1 \cdot 13)$ & $4.48(1.07)$ & $8.31(1.70)$ \\
P (period) & $17.3(0.79)$ & $18.7(0.87)$ & $29.3(2.50)$ \\
A (linear) & $1.85(0.40)$ & $1.59(0.35)$ & $1.32(0.29)$ \\
C (linear) & $2.26(0.30)$ & $2.00(0.24)$ & $2.59(0.22)$ \\
\hline
\end{tabular}

Residual standard deviation $=2 \cdot 02$.

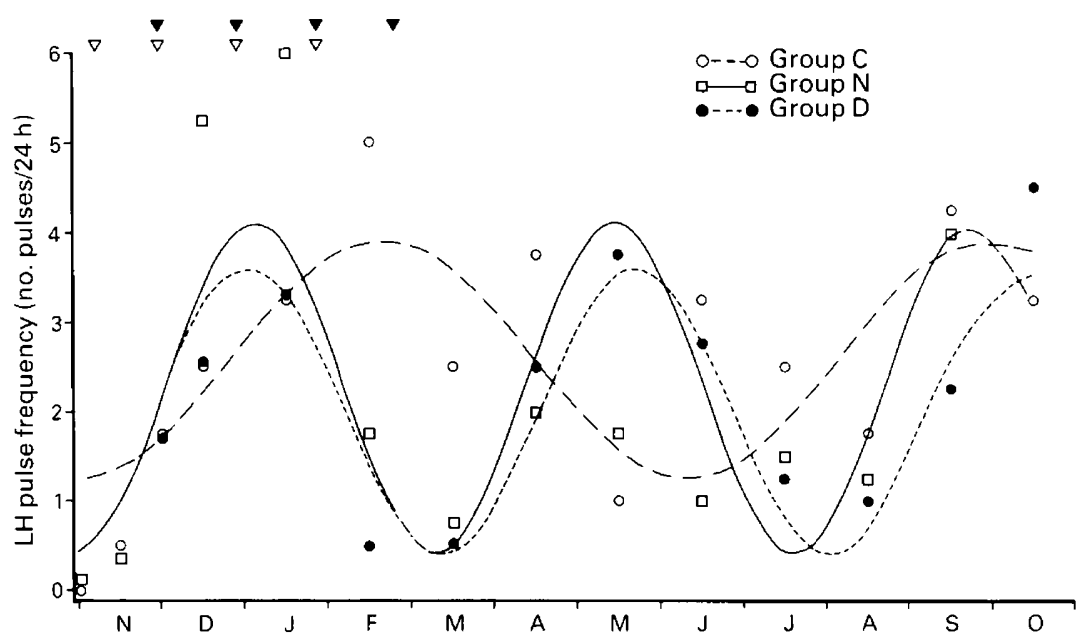

Fig. 2. Mean LH pulse frequency for rams from Exp. 1 with fitted curves for each month of the study. The lines are the fitted curves from the expression,

$$
y=\mathrm{A} \sin (2 \mathrm{phi}(t-\mathrm{phi}) / \mathrm{P})+\mathrm{B} t+\mathrm{C}
$$

where $t$ is time (in weeks) from the start of measurement, phi is a phase parameter and A, B and $\mathrm{C}$ are linear parameters. Open and closed symbol arrows indicate days when melatonin implants were given to the rams in Groups $\mathrm{N}$ and $\mathrm{D}$, respectively.

As with testis diameter, the control group was very different from the other 2 groups in period and phase, completing one period throughout the measurement period while Groups $N$ and D completed 2 periods. However, the length of period for $\mathrm{LH}$ for each group was about two-thirds that for testis diameter.

There was no significant improvement fitting separate curves for Groups $\mathrm{N}$ and $\mathrm{D}$ compared to fitting a common curve $(\mathrm{F}(4,92)=0.65)$. Thus increase in LH pulse frequency seen in control rams 
Group C
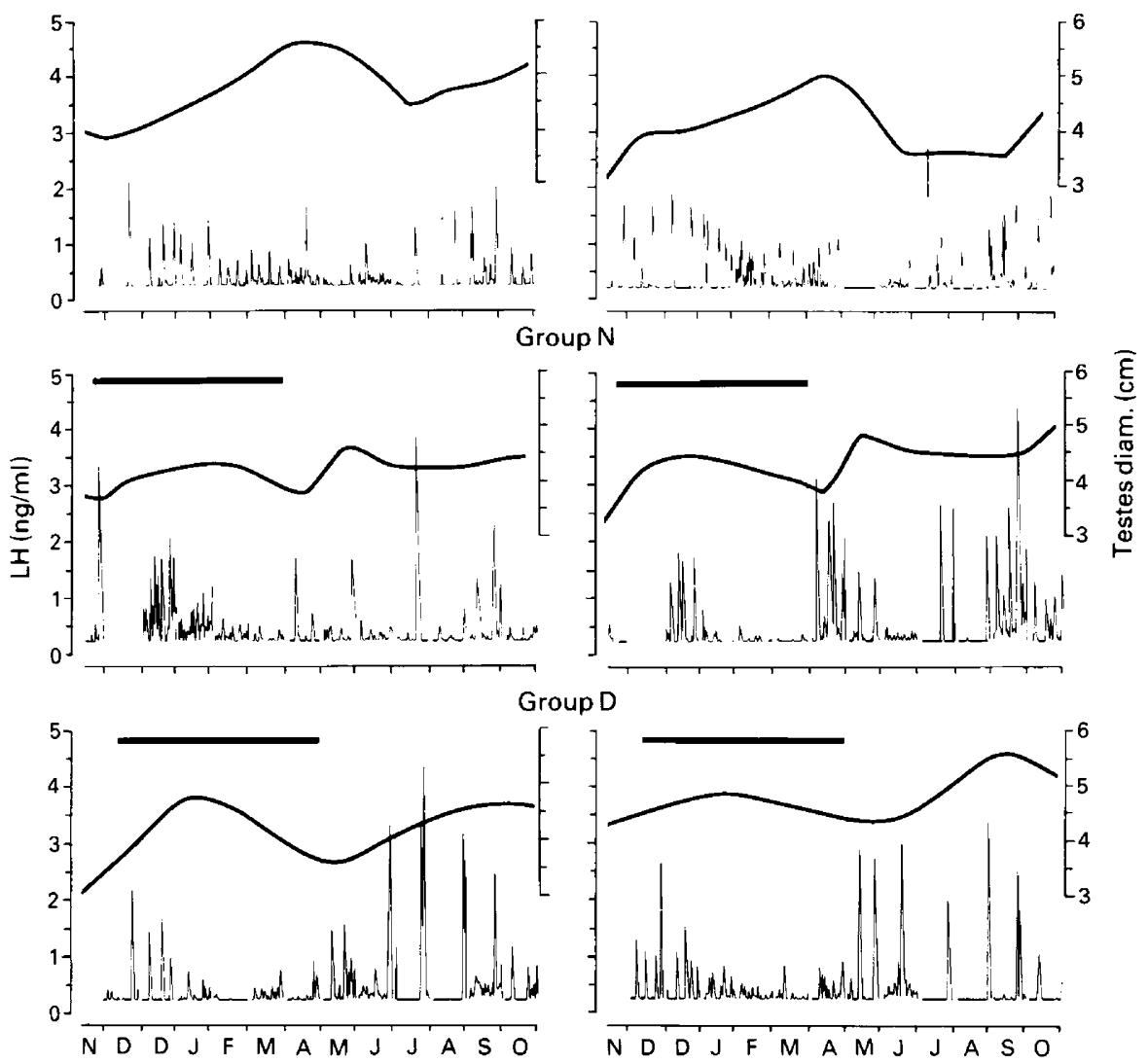

Fig. 3. Luteinizing hormone ( $\mathrm{LH})$ profiles for 2 typical individual rams from each group in Exp. 1 during each month of the study with individual testis diameter. The solid horizontal bar indicates the timing of melatonin treatment.

during summer was advanced by melatonin treatment beginning in November (Fig. 2) and a higher pulse frequency was found in Group $\mathrm{N}$ than in Groups $\mathrm{D}$ and $\mathrm{C}$ in December $(P<0.05)$. The frequency of LH pulses fell in both melatonin-treated groups in February, earlier than in control rams, and a lower pulse frequency was recorded in Groups $\mathrm{N}$ and D than in Group C in February and March $(P<0.01)$. The LH pulse frequency of the melatonin-treated rams increased and fell again between April and August and this was more pronounced in Group D which had a higher pulse frequency than Groups $\mathrm{N}$ and $\mathrm{C}$ in May $(P<0.05)$.

LH profiles and testis diameter of two typical rams from each group with the are shown in Fig. 3. The control rams had low frequency pulses of LH at the start of the study in November and December and the testes were increasing in size slowly. LH pulse frequency increased and with it testis diameter until April. The testes then regressed and LH pulse frequency was slow again in July. The testes diameter began to increase in October accompanied by more rapid LH pulses. The rams treated with melatonin in November had rapid LH pulses in December and January, but, although the testes increased in diameter, no precise peak of growth occurred. LH pulsatility was diminished in March, and in April a second period of testis growth began with high frequency LH pulses. In July and August the pulse frequency of LH was low and the testes regressed. By the end of the study, the LH pulse frequency had again begun to rise and the testes had again begun to increase in diameter. The pattern of LH pulsatility and testicular development was similar for the rams treated with melatonin in December. Peak testes diameter was reached for both rams represented in 


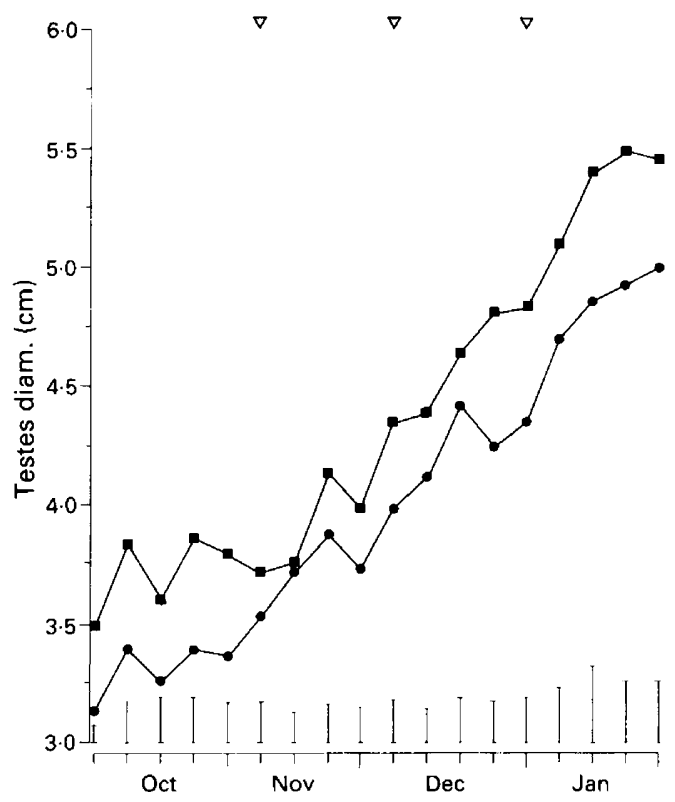

Fig. 4. Mean testes diameter of rams in Groups EM (ם) and EC (๑) in Exp. 2 throughout the study. Pooled standard errors of the mean (s.e.m.) are shown for each week. The timing of melatonin treatment is shown by the arrows.

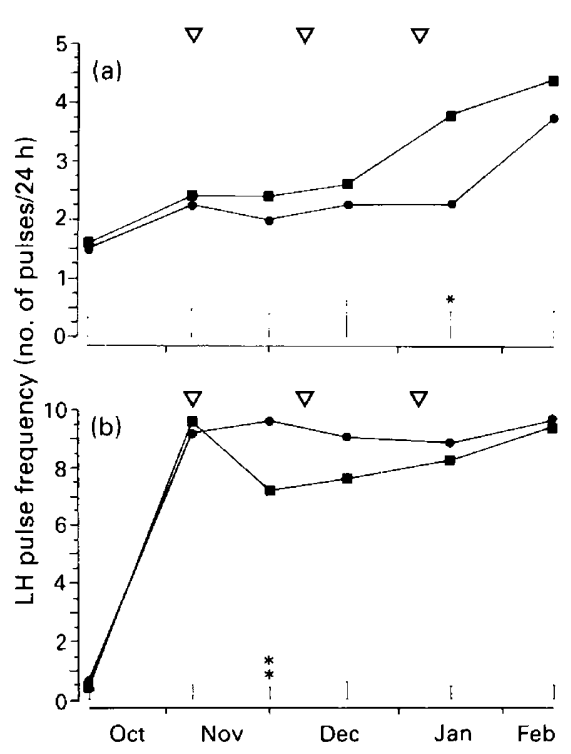

Fig. 5. Mean luteinizing hormone (LH) pulse frequency and pooled s.e.m. (vertical bars) for rams in (a) Groups EC (O) and EM ( $\mathbf{(})$ and (b) castrated rams in Groups CC (O) and CM $(\boldsymbol{D})$ in Exp. 2. Arrows indicate melatonin treatment. ${ }^{*} P<0.05 ;{ }^{* *} P<0.01$ (ANOVA). 


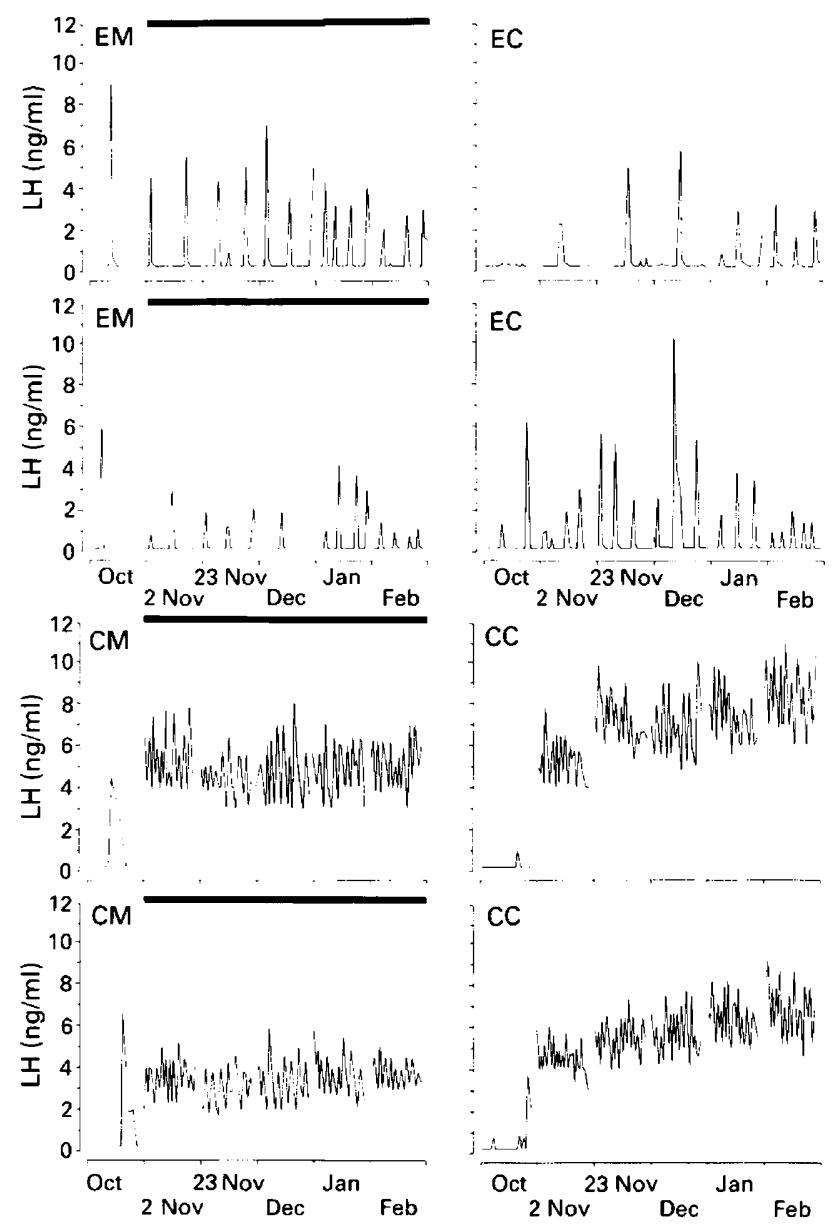

Fig. 6. Typical individual luteinizing hormone $(\mathrm{LH})$ profiles for 2 rams each from Groups EM, EC, CM and CC. Horizontal bar indicates melatonin treatment.

January. Group $\mathbf{N}$ animals had an abrupt redevelopment of testis growth in May followed by a decline, but Group D rams redeveloped more slowly to reach a peak from July-September, although the LH pulse frequency increased in May and June. LH pulsatility fell in July and August but increased again by the end of the study in October.

\section{Experiment 2: effects of treatment of entire and castrated rams with melatonin implants in early summer}

Entire rams. The testes diameter of rams in Groups EM and EC increased throughout the experimental period (Fig. 4). There was no significant difference in testes diameter between melatonin-treated and control rams on any weekly sampling date.

The LH pulse frequency of Group EC rams increased from 5 October to 2 November, remained static until January then increased again by February (Fig. 5a). The LH pulse frequency of Group EM rams followed a pattern similar to that of control rams until December then increased markedly and was higher than that of control rams in January $(P<0.05)$.

The LH pulse profiles of 2 typical rams from each of Groups EC and EM are shown in Fig. 6. LH pulse frequency was slow in all rams, but increased in Group EM rams in January, 1 month earlier than for Group EC rams. 
Castrated rams. The LH pulse frequency of rams in Groups CC and CM (Fig. 5b) had increased dramatically by 4 weeks after castration $(P<0 \cdot 001)$. The pulse frequency of Group CM rams was lower than that of Group $\mathrm{CC}$ rams on 23 November $(P<0.01)$. Between 23 November and 4 February, the pulse frequency of Group CM rams increased by $2 \cdot 2$, while that of Group CC rams remained the same (standard error of the difference $=0.56, P<0.05$ ) and the pulse frequencies of the two groups were similar by 4 February.

The LH pulse profiles of 2 typical rams in Groups CM and CC are shown in Fig. 6(b). All animals showed a conspicuous response in LH frequency and amplitude to castration. In late November the LH pulse frequency of Group CM rams was less than that for Group CC rams.

\section{Discussion}

Fitting a sine curve to the testes diameter and LH pulse frequency data effectively distinguished the controls from both melatonin treatments. Melatonin treatment significantly reduced the period (P) to about 6 months compared with $\sim 10$ months in controls. Melatonin treatment phase-advanced (phi) both LH pulse frequency and testis size, but only in testis size did November onset of treatment appear phase-advanced compared with the December onset group.

The initial effects of treatment of rams with melatonin implants beginning in November was an earlier increase in LH pulse frequency and accelerated testicular development. This advancement of testicular development is consistent with a previous experiment in which treatment of rams with melatonin implants during an artificial long ( $16 \mathrm{~h}$ light: $8 \mathrm{~h}$ dark) photoperiod also induced testicular growth (Lincoln \& Ebling, 1985). The results of the present experiment show that melatonin advanced testicular development by increasing the frequency of LH pulses and strongly suggest that melatonin has a site of action in the hypothalamus. This supports previous work on ewes in which melatonin treatment also increased LH pulse frequency (Bittman et al., 1985). Examination of individual LH profiles shows that, as in control rams, the period of enlarged testes was characterized by LH profiles with rapid, low-amplitude fluctuations in LH concentration and suggests that LH secretion was being inhibited by high steroid concentrations.

Testicular regression began in both melatonin-treated groups at about the same time, despite the different finishing dates for treatment. In Group N, regression began just as treatment ended while the testes of Group D began to regress while treatment was still continuing. Testicular regression in Group D during treatment reflected a change in response to the initial effect of melatonin treatment which was stimulatory. Refractoriness during melatonin treatment has been reported previously in rams treated with melatonin implants (Lincoln \& Ebling, 1985). In both melatonin-treated groups, testicular regression was associated with a low then increasing mean LH pulse frequency. Redevelopment of the testes appeared to lag behind this second increase in $\mathrm{LH}$ pulse frequency.

The second cycle of testicular development began in Group N in May and in Group D in June. While the differences in the date at which the second cycles started may be due to the staggered onset of treatments, the differences between groups appeared more closely related to the dates that melatonin treatment ended.

Control Coopworth rams underwent seasonal development of the testes during the experiment and this was associated with an increase in $\mathbf{L H}$ pulse frequency, particularly between January and February. Treatment of entire rams with melatonin implants resulted in a marked increase in LH pulse frequency between 6 and 10 weeks after the start of treatment, and 1 month ahead of a similar increase in control rams. The fact that there were no significant effects of melatonin treatment on testes development in the Coopworth rams may represent a breed difference; it is possible that the testes were developing as rapidly as possible and that the increased LH pulse frequency could not enhance this. A dramatic increase in LH pulse frequency was evident in all rams when sampled 4 weeks after castration. Similar effects of castration on pulse frequency were reported after castration of rams in midwinter (Schanbacher \& D'Occhio, 1984). 
Melatonin treatment of castrated rams caused a marked drop in LH pulse frequency 3 weeks after the start of treatment. This indicates that melatonin has an effect on the hypothalamus which is independent of testicular steroids. The reduction in pulse frequency in the castrated rams is an opposite effect to that found in entire rams in which melatonin increases LH pulse frequency. Although the effects of melatonin treatment with and without testicular steroids were opposite, this is unlikely to reflect opposing effects of melatonin on steroid-independent and -dependent control of the hypothalamus. The initial effect of melatonin treatment may be a slight reduction in $\mathrm{LH}$ pulse frequency although this effect is barely noticeable in entire rams with a slow rate of pulses, but is exaggerated in castrated rams which have, frequent pulses. Alternatively, stimulation of pulse frequency by melatonin treatment in a castrated ram may exceed the capacity of the pituitary to respond to the GnRH signal or exceed the ability of the hypothalamus to generate an appropriate GnRH signal. Failure of the pituitary to reflect rapid $\mathrm{GnRH}$ secretion accurately has been reported for castrated rams (Caraty \& Locatelli, 1988) and a marked depletion of hypothalamic GnRH and pituitary LH content has been reported for the ram after castration (Caraty, 1983). Finally, it could also be argued that the drop in pulse frequency was a pharmacological effect of melatonin implants which is more evident in the extremely active hypothalamo-pituitary axis of castrated rams. Measurement of GnRH pulses in hypophyseal portal blood would be necessary to answer these questions.

The reduced magnitude of the changes in $\mathrm{LH}$ secretion in castrated rams indicates that steroids secreted by the testes play a major role in maintaining normal seasonal changes in L.H. It does not necessarily imply that photoperiod has any less effect in the castrates and the neural changes induced by photoperiodic entrainment may be identical in castrated and entire rams. However, the lack of a dampening effect of steroids on LH secretion does not allow the changes in LH pulse frequency to be manifest in an animal which is near the limit of pituitary responsiveness, particularly with a longer LH clearance rate inhibiting the detection of rapid $\mathrm{LH}$ pulses. This is consistent with the view of Lincoln (1984) that steroids are not central to photoperiodic measurement, but have a secondary role in the regulation of normal reproductive functions.

The speed of the response of pulse frequency to melatonin treatment in the castrated (less than 3 weeks) compared with the entire ram (6-10 weeks) indicates that the alterations in steroid feedback may take longer to occur than those of direct photoperiodic drive. This is consistent with the temporal separation of steroid-dependent and steroid-independent effects of LH secretion in the ewe (Robinson et al., 1985) and with the evidence that different neural systems are responsible for mediating steroid feedback and steroid-independent effects on LH secretion (Meyer \& Goodman, 1986).

\section{References}

Arendt, J. (1986) Role of the pineal gland and melatonin in seasonal reproductive function in mammals. Oxford Rev. Reprod. Biol. 8, 266-320.

Bittman, E.L., Kaynard, A.H., Olster, D.H., Robinson, J.E., Yellon, S.M. \& Karsch, F.J. (1985) Pineal melatonin mediates photoperiodic control of pulsatile luteinizing hormone secretion in the ewe. Neuroendocrinology 40, 409-418.

Caraty, A. (1983) Ram hypothalamic-pituitary-gonadalinteractions. Effects of castration and cryptorchidism. Acta endocr. Copenh. 102, 292-298.

Caraty, A. \& Locatelli, A. (1988) Effect of time after castration on secretion of LHRH and LH in the ram. J. Reprod. Fert. 82, 263-269.

Goodman, R.L. \& Karsch, F.J. (1980) Pulsatile secretion of luteinizing hormone: different suppression by ovarian steriods. Endocrinology 107, 1286-1290.
Howse, A., Kennaway, D., Carbone, F., Staples, L. \& Williams, A. (1987) Comparison of ipsilateral and contralateral jugular venous melatonin levels in ewes treated with regulin implants. Proc. Aust. Soc. Reprod. Biol. 19, Abstr. 20.

Kennaway, D.J., Gilmore, T.A. \& Seamark, R.F. (1982) Effect of melatonin feeding on serum prolactin and gonadotropin levels and the onset of seasonal estrous cyclicity in sheep. Endocrinology 110, 1766-1771.

Lincoln, G.A. (1976) Secretion of LH in rams exposed to two different photoperiods. J. Reprod. Fert. 47, $351-353$.

Lincoln, G.A. (1984) Central effects of photoperiod on reproduction in the ram revealed by the use of a testosterone clamp. J. Endocr. 103, 233-24l.

Lincoln, G.A. \& Ebling, F.J.P. (1985) Effect of constant release implants of melatonin on seasonal cycles in 
reproduction, prolactin secretion and moulting in rams. J. Reprod. Fert. 73, 241-253.

Lincoln, G.A. \& Short, R.V. (1980) Seasonal breeding: Nature's contraceptive. Recent Progr. Horm. Res. 82B, 205-229.

Meyer, S.L. \& Goodman, R.L. (1986) Separate neural systems mediate the steroid-dependent and steroidindependent suppression of tonic luteinizing hormone secretion in the anestrous ewe. Biol. Reprod. 35, $562-571$.

Niswender, G.D., Reichert L.E., Jr, Midgeley A.R., Jr \& Nalbandov, A.V. (1969) Radioimmunoassay for bovine and ovine luteinizing hormone. Endocrinology 84, $1166-1173$

Pelletier, J. \& Ortavant, R. (1975a) Photoperiodic control of LH release in the ram. I. Influence of increasing and decreasing light photoperiods. Acta endocr. Copenh. 78, 435-441.

Pelletier, J. \& Ortavant, R. (1975b) Photoperiodic control of LH release in the ram. II. Light-Androgens interaction. Acta endocr. Copenh. 78, 442-450.

Pelletier, J., Garnier, D.H., de Reviers, M.M., Terqui, M. \& Ortavant, R. (1982) Seasonal variation in LH and testosterone release in rams of two breeds. $J$. Reprod. Fert. 64, 341-346.

Poulton, A.L., English, J., Symons, A.M. \& Arendt, J. (1987) Changes in plasma concentrations of $\mathbf{L H}$, FSH and prolactin in ewes receiving melatonin and short-photoperiod treatments to induce early onset of breeding activity. J. Endocr. 112, 103-111.

Robinson, J.E., Radford, H.M. \& Karsch, F.J. (1985) Seasonal changes in pulsatile luteinizing hormone (LH) secretion in the ewe: relationship of frequency of pulses to day length and response to estradiol negative feedback. Biol. Reprod. 33, 324-334.

Sanford, L.M., Howland, B.E. \& Palmer, W.M. (1984) Seasonal changes in the endocrine responsiveness of the pituitary and testes of male sheep in relation to their patterns of gonadotropic hormone and testosterone secretion. Can. J. Physiol. Pharmacol. 62, $827-833$

Schanbacher, B.D. \& D'Occhio, M.J. (1984) Hypothalamic control of the post castration rise in serum $\mathrm{LH}$ concentration in rams. J. Reprod. Fert. 72, 537-542.

Received 9 April 1990 